\title{
NMR Chemistry Analysis of Red Blood Cell Constituents in Normal Subjects and Lithium-Treated Psychiatric Patients
}

\author{
Edward F. Domino, Robert R. Sharp, Steven Lipper, \\ Christian L. Ballast, Beverly Delidow, and Michael R. Bronzo
}

Red blood cells from 18 lithium carbonate-treated patients with bipolar affective disorder and 12 normal volunteers were analyzed using ${ }^{1} \mathrm{H}$-nuclear magnetic resonance (NMR) spectroscopy. The spectra were analyzed for alanine, adenosine triphosphate (ATP), choline, 2,3-diphosphoglycerol, glucose, glutathione, glycine, and lactate. Significant elevations of choline and lactate were found in the lithium-treated patients compared with normal, unmedicated subjects. The elevation of lactate due to anaerobic metabolism in the red blood cells was further investigated via fluorometric analysis and appears to be caused by blood standing at room temperature. The observed increases in red blood cell choline are sufficiently high and statistically significant to warrant additional studies on the dramatic effects of lithium on this red cell metabolite, which might be important for an understanding of its mechanism of action in psychiatric disorders.

\section{Introduction}

Lithium salts are currently the most effective treatment for manic-depressive patients, yet the mechanism for the therapeutic action of lithium ion is unknown. Many biochemical changes appear to result from lithium treatment. Lingsch and Martin (1976) observed that the red blood cells of humans treated with lithium show an apparent "irreversible" reduction of the flux of ${ }^{14} \mathrm{C}$-choline. Paradoxically, many investigators have reported an increase of the choline levels in the red blood cells following lithium treatment (Jope et al. 1978; Ehrlich and Diamond 1980; Domino et al. 1981; Hanin et al. 1981).

In addition to changes in red blood cell choline levels, Shea et al. (1981) and Pomara et al. (1983) reported that glycine accumulates in the human red cells following chronic lithium treatment. Although lithium treatment alters the concentrations of these cellular

From the Departments of Pharmacology,, Chemistry, and Psychiatry, University of Michigan, Ann Arbor, MI.

Address reprint requests to Dr. E. F. Domino, Department of Pharmacology, Box 035, M6414 Medical Science Building I, University of Michigan, Ann Arbor, MI 48109-0010.

Supported in Part by NIMH Grant USPHS MH 37210, the Psychopharmacology Research Fund (E.F.D.), and the Research Fund, Department of Psychiatry (Lipper via Carroll).

Received August 3, 1984; revised May 16, 1985. 
metabolites, no acceptable biological marker of lithium therapy exists. This study used nuclear magnetic resonance (NMR) analysis of the red blood cells from lithium-treated patients to provide a simultaneous determination of several intracellular constituents, thereby allowing a greater probability of finding further metabolic changes induced by chronic lithium treatment and possibly a clinically useful marker of lithium therapy.

\section{Methods}

Human use approval for this study was obtained from the University of Michigan Medical Center Committee to Review Grants for Clinical Research Involving Human Beings. Venous blood from 12 normal volunteers was drawn into $10-\mathrm{ml}$ heparinized vacutainers and placed immediately on ice. Blood was also drawn from 18 lithium-treated psychiatric patients who met the DSM-III criteria (Spitzer et al. 1978) for bipolar affective disorders. Venous blood from patients was also drawn into 10-ml heparinized vacutainers, but a variable amount of time (from immediately to $1 \mathrm{hr}$ ) occurred between the blood being drawn and being put on ice. The patients consisted of 16 women and 2 men, who had lithium therapy of duration ranging from 1 month to 10 years. The patients had plasma lithium values ranging from 0.27 to $1.33 \mathrm{meq} / \mathrm{liter}$ red blood cells, with the average being $0.87 \pm 0.07 \mathrm{meq} / \mathrm{liter}$ red blood cells. The majority of these patients were euthymic at the time the blood sample was drawn, primarily for assessing their lithium levels on maintenance therapy.

The blood samples were centrifuged for $10 \mathrm{~min}(600-900 \times \mathrm{g})$, and the plasma was decanted for lithium determination. An equal volume of $10 \%$ trichloroacetic acid (TCA) was added to the red blood cells to denature protein, which was removed as a precipitate after centrifuging (15-20 min, 600-900 $\times \mathrm{g}$ ). The $\mathrm{pH}$ of the supernatant was adjusted to 6.5-7.0 with $2 \mathrm{M} \mathrm{Na}_{2} \mathrm{CO}_{3}$, and a small amount of Chelex $(10 \% \mathrm{w} / \mathrm{w})$ was added to remove the paramagnetic ions, chiefly $\mathrm{Fe}^{3+}$ which, if not removed, would broaden the NMR peaks. The solution was stirred for several hours, then frozen in liquid nitrogen and lyophilized overnight. The remaining precipitate was brought up to $600 \mu$ l with $D_{2} 0$ and 2,2-dimethyl-2-sila-pentane-5-sulfonic acid (DSS) added as the internal standard to a final concentration of $0.5 \mathrm{mM}$. The ${ }^{1} \mathrm{H}-\mathrm{NMR}$ spectrum of the solutions was taken on a Bruker WM 360 NMR spectrometer.

NMR peak identification was established by (1) reference spectra of known metabolites and (2) additions of reference compounds to prepared red blood cell lyophilates. The NMR peaks were quantitated by comparing peak integrals with the integral of the DSS standard and accounting for the different number of protons represented by the different NMR peaks. The concentration of the components in the red blood cells was calculated using the approximation of $11.4 \times 10^{9} \mathrm{cells} / \mu \mathrm{l}$ packed red blood cells.

In addition, red blood cell lactate levels also were analyzed over time using an enzymic fluorometric analysis by the method of Lloyd et al. (1978). Blood was drawn from two normal volunteers and two euthymic bipolar patients on chronic lithium. The blood was subjected to three different treatments: (1) placed immediately on ice; (2) placed immediately at room temperature; (3) placed on ice followed by warming to room temperature. The blood was centrifuged at $2500 \mathrm{rpm}$ for $5 \mathrm{~min}$ to pack the red blood cells. At $15-\mathrm{min}$ intervals, $0.5-\mathrm{ml}$ samples of the packed red blood cells were denatured by addition to $0.5 \mathrm{ml}$ concentrated perchloric acid, followed by $1 \mathrm{~min}$ of vortexing. These solutions were then fluorometrically analyzed for lactate. 


\section{Results}

A typical NMR spectrum of the lyophilates of red blood cells of a normal control and a lithium-treated patient are shown in Figure 1. The peak assignments are as illustrated. The alanine peak was undetectable in about half the samples. The glycine peak was obscured by the many small peaks from $3.2-4 \mathrm{ppm}$, which were attributed to glucose. Glycine was therefore difficult to quantify.

Mean \pm SD data for a maximum of 18 patients and 9 normal volunteers are presented in Table 1, along with literature values. Compared with previously published literature, the mean concentrations of red blood cell lactate were too high and glucose too low, suggesting a possible artifact of anaerobic metabolism. The values for glutathione, 2,3diphosphoglycerol (2,3-DPG), glucose, alanine, glycine, and adenosine triphosphate (ATP) were not significantly different for lithium-treated patients and normal volunteers by Student $t$-test. In addition, except for glucose, they were roughly comparable to those previously described in the literature. The mean red blood cell choline level in the lithiumtreated patients was more than five times greater than the mean red blood cell choline level in the normal volunteers. Lactate levels also were significantly elevated in lithiumtreated patients compared with the normal volunteers.

Figure 1. 'H-NMR spectra of red blood cell lyophilates. Representative ${ }^{1} \mathrm{H}-\mathrm{N} M \mathrm{R}$ spectra are given for both a normal volunteer and a lithium carbonate-treated patient. The peaks identified on the spectra are only those used for metabolite quantitation. The alanine peak is virtually absent in both these spectra. The many small peaks from 3.2 to $4.0 \mathrm{ppm}$ are due to glucose; however, only the peak at $5.25 \mathrm{ppm}$ was used to quantify glucose. The peaks of each spectrum were compared with the internal standard (DDS) for quantification.

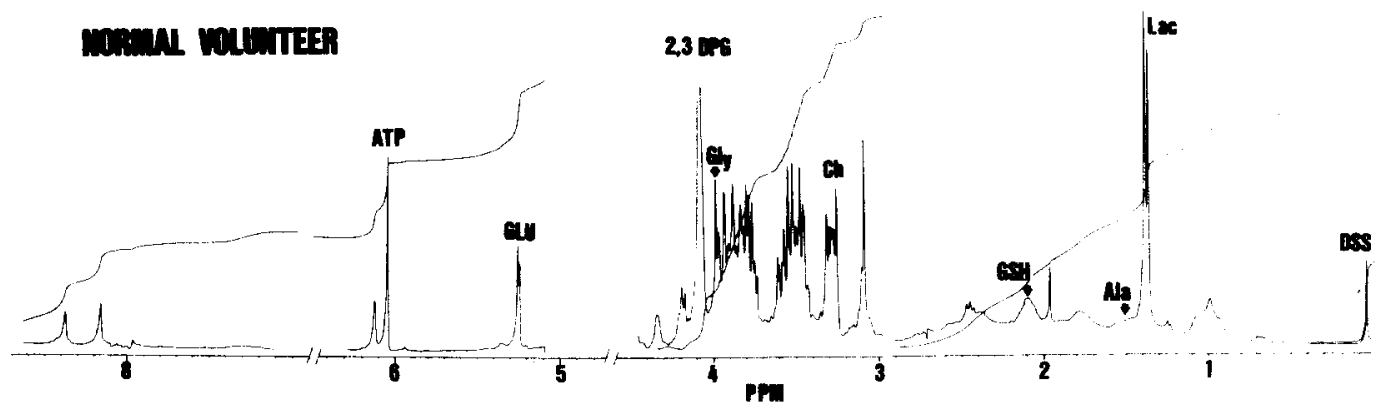

\section{LTTIUI TREATED PATIENT}

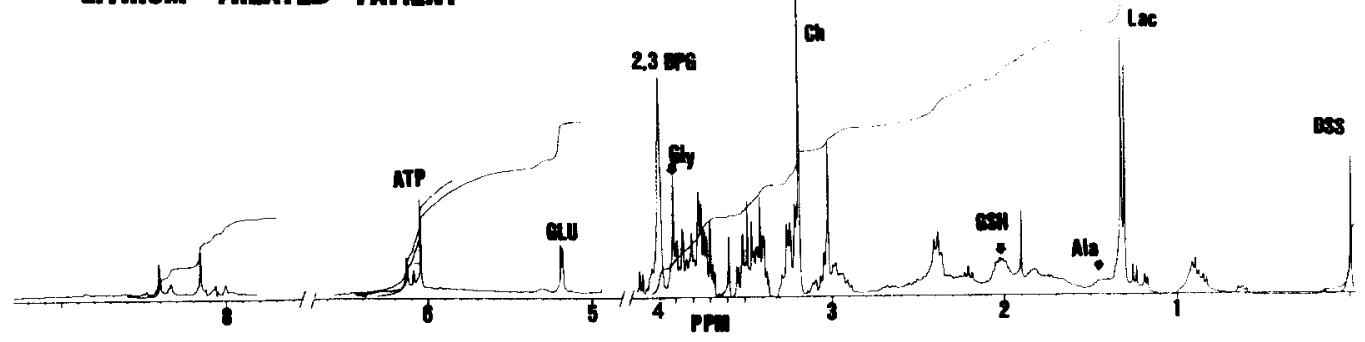


Table 1. Blood Constituents Measured in Normal Volunteers and Li-Treated Patients

\begin{tabular}{|c|c|c|c|c|}
\hline Substance & $\begin{array}{c}\text { Normal } \\
\text { volunteers }\end{array}$ & $\begin{array}{l}\text { Lithium-treated } \\
\text { patients }\end{array}$ & $\begin{array}{l}\text { Previously reported } \\
\text { concentrations } \\
\text { for normals }\end{array}$ & References \\
\hline $\mathrm{Li}$ & - & $0.88 \pm 0.08(18)$ & - & \\
\hline Lactate $^{a}$ & $0.76 \pm 0.11(9)^{b}$ & $1.40 \pm 0.11(18)$ & $0.372 \pm 0.073$ & Foster et al. 1978 \\
\hline Glutathione & $1.13 \pm 0.16(9)$ & $0.81 \pm 0.08(18)$ & $2.33 \pm 0.13$ & Hagenfeldt et al. 1978a \\
\hline Choline $^{a}$ & $0.05 \pm 0.01(8)$ & $0.26 \pm 0.04(18)$ & $0.010-0.100$ & Domino et al. 1981 \\
\hline 2,3-DPG & $3.29 \pm 0.37(9)$ & $2.79 \pm 0.17(18)$ & $3.6-5.0$ & Vanderheiden 1961 \\
\hline Glucose & $0.54 \pm 0.08(9)$ & $0.65 \pm 0.08(16)$ & $2.88 \pm 0.44$ & Foster et al. 1978 \\
\hline Alanine & $0.19 \pm 0.04(3)$ & $0.36 \pm 0.08(6)$ & $0.183-0.363$ & Foster et al. 1978 \\
\hline Glycine & $0.32 \pm 0.05(6)$ & $0.47 \pm 0.11(5)$ & $0.258-0.500$ & Hagenfeldt et al. $1978 \mathrm{~b}$ \\
\hline ATP & $0.05 \pm 0.07(9)$ & $0.48 \pm 0.05(18)$ & 0.452 & Bartlett and Marlow 1953 \\
\hline
\end{tabular}

${ }^{a} p<0.05$, two-tailed $t$-test.

${ }^{b}$ All figures are expressed in mmol/liter of packed red blood cells. The numbers in parentheses indicate the number of subjects included, as NMR peaks could not be adequately separated for each spectrum.

For further analysis, the patients were divided into two groups: (1) three patients who had been on lithium carbonate treatment less than 4 months but more than 1 month, and (2) 12 patients who had been on lithium carbonate treatment more than 4 months. Three patients were eliminated because the duration of their lithium therapy was unclear. This analysis appears in Table 2 . The lactate levels for patients in the short-term lithium treatment group were significantly different $(p<0.05)$ from those in the long-term lithium treatment group; the lactate levels for both the long- and short-treatment groups were significantly different from the normal group's $(p<0.05)$.

Inasmuch as anaerobic metabolism can elevate lactate levels, additional studies were done in which red blood cells were allowed to stand in ice as well as at room temperature. Blood lactate was measured fluorometrically in the latter study. Significant and similar increases in red cell lactate levels were found as expected when the red blood cells from two normal subjects and two lithium-treated patients were allowed to stand at room temperature. Some typical time analyses of red blood cell lactate levels as a function of

Table 2. RBC Constituents in Li-Treated Patients as a Function of Duration of Treatment

\begin{tabular}{|c|c|c|}
\hline \multirow[b]{3}{*}{ Substance } & Group 1 & \multirow[b]{2}{*}{ Group 2} \\
\hline & Treatment more than 1 month & \\
\hline & and less than 4 months & Treatment more than 4 months \\
\hline Lactate $^{a}$ & $1.85 \pm 0.32(3)^{b}$ & $1.35 \pm 0.10(12)$ \\
\hline GSH & $0.92 \pm 0.37$ & $0.83 \pm 0.09(12)$ \\
\hline Choline & $0.23 \pm 0.06(3)$ & $0.30 \pm 0.06(12)$ \\
\hline 2,3-DPG & $2.88 \pm 0.09$ & $2.91 \pm 0.17(12)$ \\
\hline Glucose & $0.81 \pm 0.35$ & $0.64 \pm 0.11(11)$ \\
\hline Alanine & 0.50 & $0.25 \pm 0.06(4)$ \\
\hline Glycine & $-\quad(0)$ & $0.47 \pm 0.11(5)$ \\
\hline ATP & $0.47 \pm 0.01$ & $0.52 \pm 0.06(12)$ \\
\hline
\end{tabular}

${ }^{a} p<0.05$, two-tailed $t$-test.

${ }^{b}$ All figures are expressed in mmol/liter of packed red blood cells. The numbers in parentheses indicate the number of subjects included, as NMR peaks could not be adequately separated for each spectrum. 


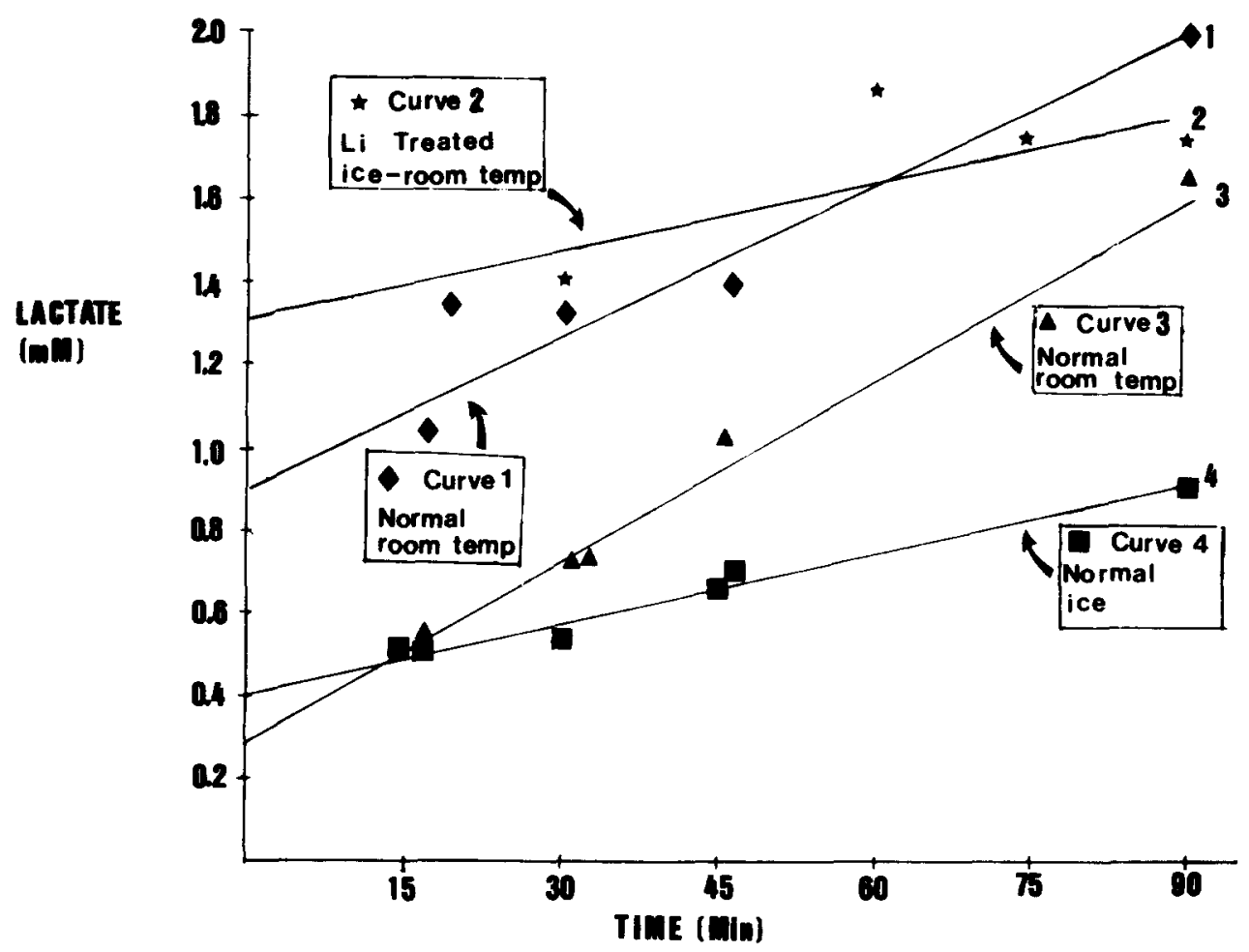

Figure 2. Effect of environmental temperature on red blood cell lactate levels. Lactate levels were assayed fluorometrically. (1 and 3) Blood from a normal volunteer kept at room temperature. (2) Blood from a lithium-treated patient left on ice for $49 \mathrm{~min}$, then warmed to room temperature and left at room temperature. (4) Blood from a normal volunteer kept in ice.

environmental temperature are shown in Figure 2. The increase in red blood cell lactate was similar in both the normal volunteers (2) and lithium-treated patients (2). Hence, the increase in red blood cell lactate levels observed by NMR analysis in the lithium-treated patients could have been due to differences in blood standing at room temperature.

\section{Discussion}

The choline increase reported for lithium-treated patients using the NMR method in this study was roughly a fivefold increase, compared to a roughly 20 -fold increase for a gas chromatographic method also used in this lab (Domino et al. 1981). This discrepancy is probably due to differences in individual patient variability and chemical methodologies, particularly differences in extraction before analysis. It has been previously reported that enormous differences in red cell choline are frequently observed even in patients with similar doses and duration of lithium therapy (Domino et al. 1981).

It should be noted that in a previous NMR study of red blood cell metabolism, Brown et al. (1977) reported that a peak at approximately $2.7 \mathrm{ppm}$ was acetylcholine. In subsequent studies, this error in NMR peak assignment has been corrected (Jones and Kuchel 1980). 
Shea et al. (1981) as well as Pomara et al. (1983) reported a significant increase (about $30 \%$ ) in red blood cell glycine in lithium-treated patients. Shea et al. reported this increase in normal volunteers compared to lithium-treated patients, whereas Pomara et al. reported a slightly lower increase for patients before lithium treatment compared to during lithium treatment. Using the NMR methodology described in this article, no differences in glycine levels were found between normal volunteers and lithium-treated patients. However, it should be noted that the glycine peak was one of the most difficult to distinguish and, as a result, glycine values were obtained for only 5 of 18 lithium-treated patients and 6 of 9 normal volunteers, thus distorting the results.

The observed increase in red cell lactate for lithium-treated patients versus normal volunteers deserves further comment. As the blood from the lithium-treated patients may have stood at room temperature for an indeterminant amount of time (from less than 1 min up to $1 \mathrm{hr}$ ), the increased lactate levels are probably due to normal anaerobic glucose metabolism. The fluorometric analysis showed neither a difference in lactate levels between the normal volunteers and lithium-treated patients, nor a difference between the increases in lactate with time. One finding that still remains unexplained is that patients treated longer than 1 month but less than 4 months with lithium had slightly larger red blood cell lactate levels.

Obviously, further studies on red cell lactate levels in lithium-treated patients should be performed. Nevertheless, on the basis of this preliminary study, one must conclude that the increase in red blood cell lactate is probably an artifact due to blood standing for even a short period of time at room temperature. Future studies must keep in mind differences between aerobic and anaerobic metabolism and the effect of environmental temperature on red blood cell constituents.

The authors would like to acknowledge the help of Drs. Greden, Haraharahan, Richie, and Martin in this study.

\section{References}

Bartlett GR, Marlow AA (1953): Erythrocyte carbohydrate metabolism; chromatographic isolation of monophosphoglycerate, diphosphoglycerate, and adenosine triphosphate and their metabolic turnover with glucose carbon. J Lab Clin Med 42:188-192.

Brown FF, Campbell ID, Kuchell PW, Rabenstein DL (1977): Human erythrocyte metabolism studies by 'H spin-echo NMR. FEBS Lett 82:12-16.

Dittmer DS (ed) (1961): Blood and Other Body Fluids. Washington, DC: Federation of American Societies for Experimental Biology.

Domino EF, Mathews B, Tait SK, Demetriou SK, Fucek F (1981): Red blood cell/plasma choline ratio-A possible biological marker of lithium therapy: Clinical correlations and limitations. In Pepeu G, Ladinsky H (eds), Advances in Behavioral Biology 25: Cholinergic Mechanisms. New York: Plenum Press, pp 891-900.

Ehrlich BE, Diamond JM (1980): Lithium, membranes and manic-depressive illness. J Membr Biol 52:187-200.

Foster KJ, Alberti KGM, Hinks L, Lloyd B, Postle A, Smythe P, Turnell DC, Walton R (1978): Blood intermediary metabolite and insulin concentrations after an overnight fast: Reference ranges for adults and interrelations. Clin Chem 24:1568-1572.

Hagenfeldt L, Arvidson A, Larsson A (1978a): Glutathione and gamma-glutamylcysteine in whole blood, plasma and erythrocytes. Clin Chim Acta 85:167-173. 
Hagenfeldt L, Larsson A, Andersson R (1978b): The $\gamma$-glutamyl cycle and amino acid transport. N Engl J Med 299:587-590.

Hanin I, Spiker DG, Mallinger AG, Kopp U, Himmelhoch JM, Neil JF, Dupfer DG (1981): Blood choline and its meaning in psychiatric and neurologic disease states. In Pepeu G, Ladinsky H (eds), Advances in Behavioral Biology 25: Cholinergic Mechanisms. New York: Plenum Press, pp 901-919.

Jones AJ, Kuchel PW (1980): Measurement of choline concentration and transport in human erythrocytes by ${ }^{1} \mathrm{H}$-NMR: Comparison of normal blood and that from lithium-treated psychiatric patients. Clin Chim Acta 104:77-85.

Jope RS, Jenden DJ,, Ehrlich BE, Diamond JM (1978): Choline accumulation in erythrocytes during lithium therapy. $N$ Engl J Med 299:833-834.

Lingsch C, Martin K (1976): An irreversible effect of lithium administration to patients. $\mathrm{Br} J$ Pharmacol 57:323-327.

Lloyd B, Burrin J, Smythe P, Aberti KG (1978): Enzymic fluorometric continous-flow assays for blood glucose, lactate, pyruvate, alanine, glycerol, and 3-hydroxybutyrate. Clin Chem 24:1724-1729.

Pomara N, Banay-Schwartz M, Block R, Stanley M, Gershon S (1983): Elevation of RBC glycine and choline levels in geriatric patients treated with lithium. Am J Psychiatry 140:911-913.

Shea PA, Small JG, Hendrie HC (1981): Elevation of choline and glycine in red blood cells of psychiatric patients due to lithium treatment. Biol Psychiatry 16:825-830.

Spitzer RL, Endicott J, Robins E (1978): Research Diagnostic Criteria: rationale and reliability. Arch Gen Psychiatry 35:773-782.

Vanderheiden BS (1961): Ribosediphosphate in the human erythrocyte. Biochem Biophys Res Commun 6:117-123. 